\title{
Wind variability in the Canary Current during the last 70 years
}

\author{
Nerea Marrero-Betancort, Javier Marcello, Dionisio Rodríguez Esparragón, and Santiago Hernández-León \\ Instituto de Oceanografía y Cambio Global (IOCAG), Universidad de Las Palmas de Gran Canaria, Unidad Asociada \\ ULPGC-CSIC, Las Palmas de Gran Canaria, 35017, Spain
}

Correspondence: Nerea Marrero-Betancort (nerea.marrero102@alu.ulpgc.es)

Received: 3 March 2020 - Discussion started: 25 March 2020

Revised: 5 June 2020 - Accepted: 9 July 2020 - Published: 6 August 2020

\begin{abstract}
Climate evolves following natural variability, and knowledge of these trends is of paramount importance to understand future scenarios in the frame of global change. Obtaining local data is also of importance since climatic anomalies depend on the geographical area. In this sense, the Canary Current is located in one of the major eastern boundary current systems and is mainly driven by the trade winds. The latter promote Ekman transport and give rise to one of the most important upwelling zones of the world on the northwest African coast. Nearly 30 years ago, Bakun (1990) raised a hypothesis contending that coastal upwelling in eastern boundary upwelling systems (EBUSs) might be intensified by global warming due to the enhancement of the trade winds, increasing pressure differences between the ocean and the continent. Using available NCEP/NCAR wind data north of the Canary Islands from 1948 to 2017, we show that trade wind intensity experienced a net decrease of $1 \mathrm{~m} \mathrm{~s}^{-1}$. Moreover, these winds are strongly influenced, as expected, by large-scale atmospheric patterns such as the North Atlantic Oscillation (NAO). In addition, we found a relationship between the wind pattern and the Atlantic Multidecadal Oscillation (AMO), indicating that the ocean contributes to multidecadal atmospheric variability in this area of the ocean with a considerable lag ( $>10$ years).
\end{abstract}

\section{Introduction}

The just-released Intergovernmental Panel on Climate Change (IPCC) special report on the ocean and cryosphere in a changing climate (SROCC) (IPCC, 2019) details the immense pressure that climate change is exerting on ocean ecosystems and portrays a disastrous future for most life in the ocean and for the billions of people who depend on it. These ocean ecosystems of paramount importance for fisheries include the eastern boundary current systems (EBCSs). The four major EBCSs are the California, Canary, Benguela, and Humboldt systems (Bakun and Nelson, 1991). The EBCSs cover a surface area of only $\sim 2 \%$ of the global oceans but produce about $20 \%$ of the total for the world's fisheries (Pauly and Christensen, 1995). Currently, research on the response of EBCSs and the associated impact under a global climate change scenario is motivating numerous studies over different time periods (Barth et al., 2007; McGregor et al., 2007; Arístegui et al., 2009; Pardo et al., 2011). These recent analyses, covering the variability of physical, geological, biological, and chemical characteristics in EBCSs in relation to global climate change, are rather controversial because of the different results (Pardo et al., 2011).

A long-standing hypothesis contends that coastal upwelling in EBCSs might be intensified as an effect of global warming (Bakun, 1990). Trade winds could be intensified because of the increase in the pressure gradient between the continents and the ocean, promoting an increase in Ekman pumping in the coastal zone. Thus, as global warming progresses an increase in trade wind intensity in those areas is expected. These changes in the ocean physics would provide more nutrients and therefore primary productivity, fueling upper trophic levels such as an increase in fish crop.

In this context, several studies reveal an increase in the strengthening of upwelling in the main eastern boundary upwelling systems (EBUSs) of the world such as California, Humboldt (Chile-Peru), Canary, and Benguela (Demarcq, 2009; Gutiérrez et al., 2011; Lima and Wethey, 2012; Santos et al., 2012a, b; Cropper et al., 2014; Sydeman et al., 2014; Benazzouz et al., 2015; Varela et al. 2015). Sydeman et al. (2014) performed a meta-analysis of the literature on upwelling-favorable wind intensification, with results 

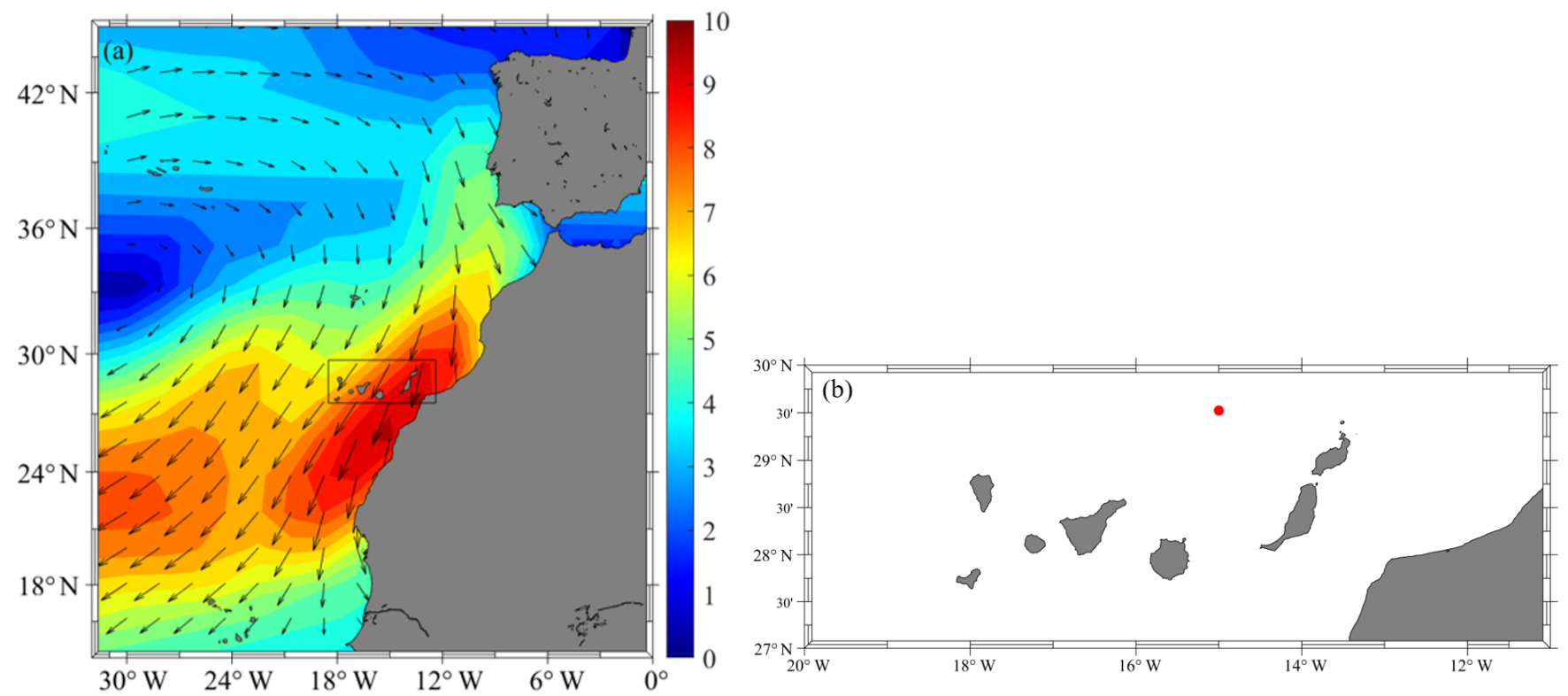

Figure 1. (a) Geographic area of Macaronesia during the trade wind season. Inset shows the study zone. The wind intensity (m $\mathrm{s}^{-1}$ ) is colored, and the wind direction is represented by the arrows. (b) Canary archipelago (the red dot represents the geographical location of the study area).
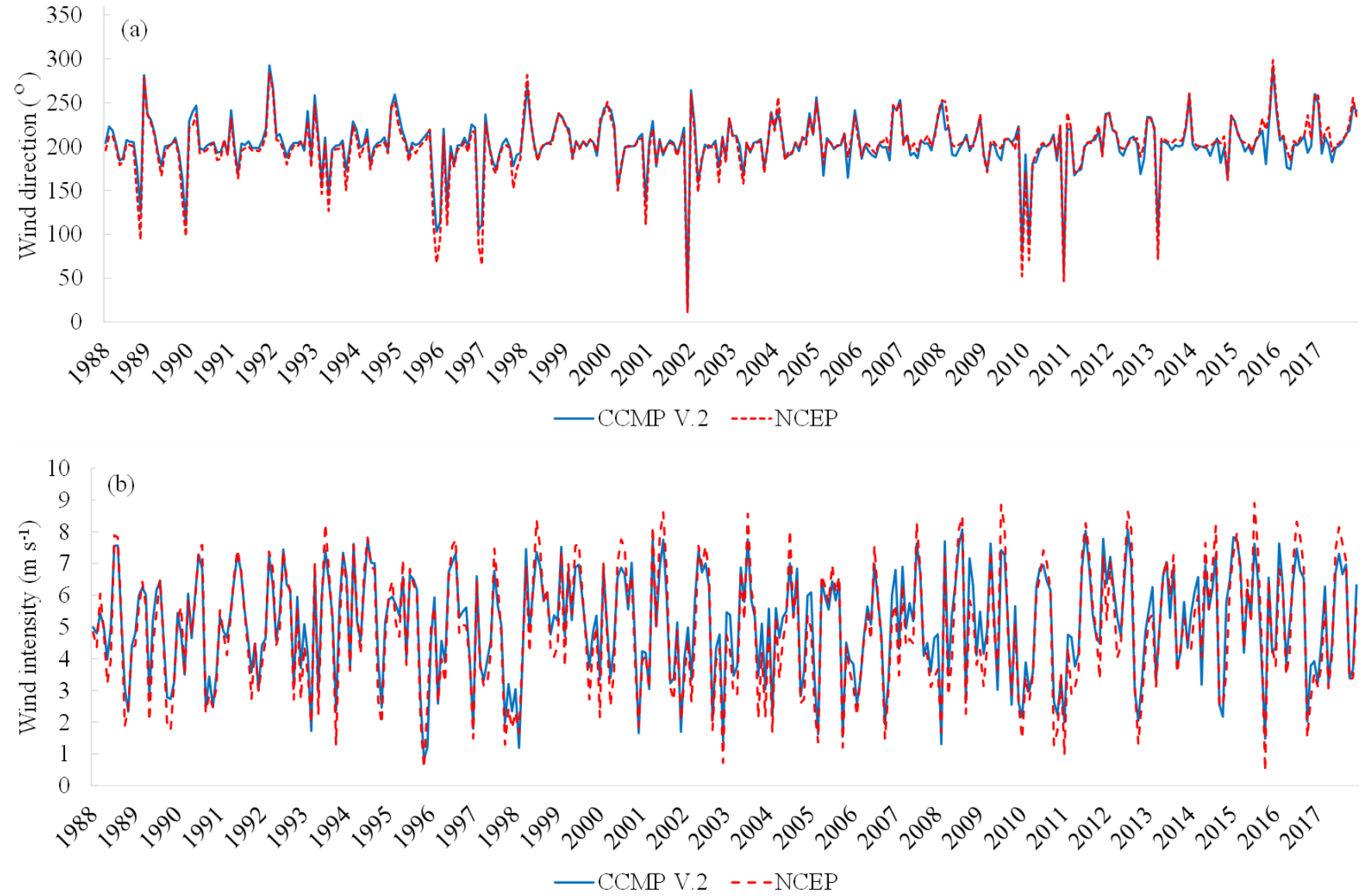

Figure 2. Correlation between CCMP V.2 and NCEP. (a) Wind direction (degrees). (b) Wind intensity ( $\mathrm{m} \mathrm{s}^{-1}$ ). 

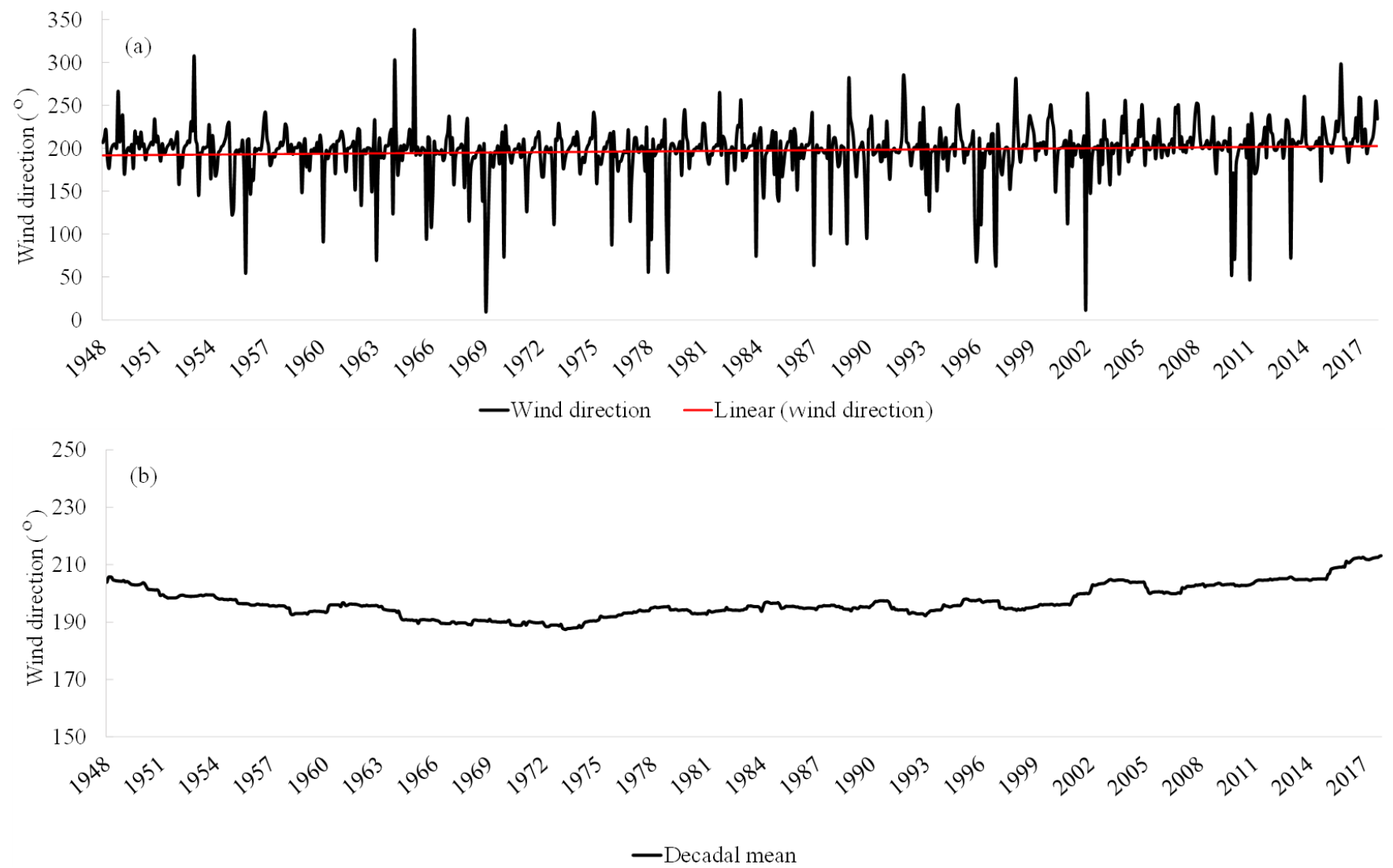

Figure 3. Time series of (a) the wind direction with its linear regression and (b) the 10-year moving average of the wind direction.

from 22 studies published between 1990 and 2012 based on time series ranging in duration from 17 to 61 years. This research illustrated that winds have intensified in the California, Benguela, and Humboldt upwelling systems. However, wind change is equivocal in the Canary system. In this sense, the 40-year study (1967-2017) performed by Barton et al. (2013) analyzing the atmospheric and oceanic variables involved in the Canary EBUS showed a lack of statistically significant change in the meridional wind component (upwelling favorable).

Recently, Bonino et al. (2019) found sharp differences in Atlantic and Pacific upwelling areas, highlighting the uniqueness of each EBUS and observing a negative upwelling trend connected to the low frequency of the Atlantic Multidecadal Oscillation (AMO) in the Canary Current system. Therefore, the negative trend observed could be the result of the longterm variability of the AMO index.

Thus, uncertainty about the behavior of the wind patterns in the Canary Current promotes considerable concern in vulnerable areas such as the Canary Islands due to their expected alterations due to climate change (Kelman and Khan, 2013; Nurse et al., 2014). Therefore, we have analyzed changes in wind patterns during the last 70 years (1948-2017) in this archipelago in order to explore the connections to future cli- mate change and the North Atlantic global circulation patterns.

\section{Material and methods}

\subsection{Study area}

In order to study long-term trends in wind direction and intensity in the Canary Current, the present study mainly addresses the analysis of the trade winds as a main event in the climate of the region. As they blow from the northeast direction, we selected a location to the north of the archipelago $\left(29.52^{\circ} \mathrm{N}, 15^{\circ} \mathrm{W}\right.$, Fig. 1$)$, away from the coast, to avoid disturbances due to island orography and because it is close to the European Oceanic Time Series Station of the Canary Islands (ESTOC; Neuer et al., 2007). Moreover, we discarded locations to the south of the archipelago as they are quite disturbed by the islands over hundreds of kilometers. 

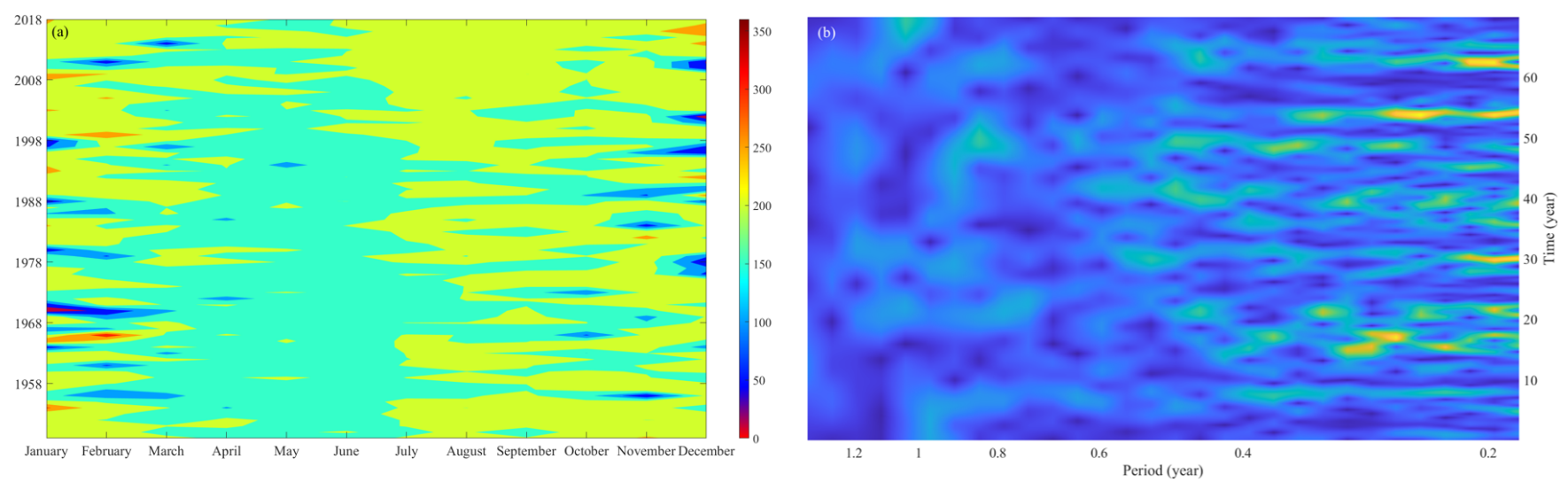

Figure 4. (a) Monthly variations of the wind direction ( $x$ axis) over the years ( $y$ axis). The palette is polar; that is, it begins and ends in the same color so that the angular variation between 0 and $360^{\circ}$ is intuitively appreciated. (b) Wavelet analysis of the wind direction.

\subsection{Data}

The wind data used in this study were produced by the National Atmospheric Prediction Center and the United States National Atmospheric Research Center (NCEP/NCAR). They are provided by the Physical Sciences Division (PSD) of the National Oceanic and Atmospheric Administration (NOAA) (Kalnay et al., 1996). These data correspond to a reanalysis of the monthly means of the zonal $(u)$ and meridional $(v)$ components of the wind measured at $10 \mathrm{~m}$ of height. They are supplied in a matrix of 192 pixels in longitude and 94 pixels in latitude (Gaussian grid), with a geographical resolution of $2.5^{\circ} \times 2.5^{\circ}$. For our study, the time period between January 1948 and December 2017 was chosen, covering a total of 70 years.

Additionally, data derived from the Cross-Calibrated Multi-Platform (CCMP) project were also analyzed, combining a series of calibrated satellite wind data obtained by remote sensors; they are supplied and disseminated by Remote Sensing Systems (RSS) (Atlas et al., 1996, 2011; Hoffman et al., 2003). The CCMP V.2 data consist of monthly averages of the zonal and meridional components of the wind, also measured at $10 \mathrm{~m}$ of height. They are supplied in a matrix of 1440 pixels in longitude and 628 pixels in latitude, with a geographical resolution of $0.25^{\circ} \times 0.25^{\circ}$. These data have a temporal range lower than the NCEP, spanning a period of time from January 1988 to December 2017 for a total of 30 years.

\subsection{Methodology}

The NCEP and CCMP V.2 data used have a level 3.5 processing, and a preliminary filter was applied to eliminate anomalous data such as outliers and negative velocity data values. Next, we extracted the subset of wind data of interest for this study corresponding to the area between 27 and $30^{\circ} \mathrm{N}$ and 11 to $20^{\circ} \mathrm{W}$. Thereafter, wind intensity and direction were calculated from the zonal and meridional wind components. Subsequently, we performed different correlation analyses between CCMP V.2 and NCEP data. As a result of the high correlation achieved between the two datasets, the time period between January 1948 and December 2017 was chosen in order to cover the range of 70 years that allows for a more complete wind analysis. The oceanographic standard was used to describe the wind; this is the direction towards which the wind blows, taking geographical north $\left(0^{\circ}\right)$ as a reference and measuring the angle clockwise.

\section{Results}

In order to select the most appropriate dataset for this study, as indicated, we carried out a preliminary statistical analysis of the correlation between the NCEP data and the CCMP V. 2 series. The study covered the 30 -year period in which data are available from both sources (from 1988 to 2017). The datasets were highly correlated in both direction $(r=0.964$; Fig. 2a) and intensity $(r=0.961$; Fig. 2b). According to these results, we decided to choose the NCEP data for the study because the time range is considerably longer. There are several wind databases, such as the Climate Forecast System Reanalysis (CFSR) (Saha et al., 2010, 2014), but they were not considered as they have a shorter temporal coverage than the NCEP/NCAR dataset.

Time series of wind direction showed a linear regression with a slope of $0.013^{\circ}$ for the entire period, which implied a total variation in direction of $10.7^{\circ}$ after 70 years. Thus, the wind direction during the complete period of study varied slightly, with a net trend to rotate clockwise. The average wind direction value was $197^{\circ} \pm 35.5^{\circ} \mathrm{SD}$, which is the usual direction of the trade winds in the study area. The most remarkable anomalies occurred in autumn and winter at 338, 15 , and $11^{\circ}$ in February 1965, January 1969, and December 2001, respectively (Fig. 3a). The 10-year moving average (Fig. 3b) showed a change in the wind direction until the early 70 s, indicating a counterclockwise rotation. How- 
N. Marrero-Betancort et al.: Wind variability in the Canary Current

955
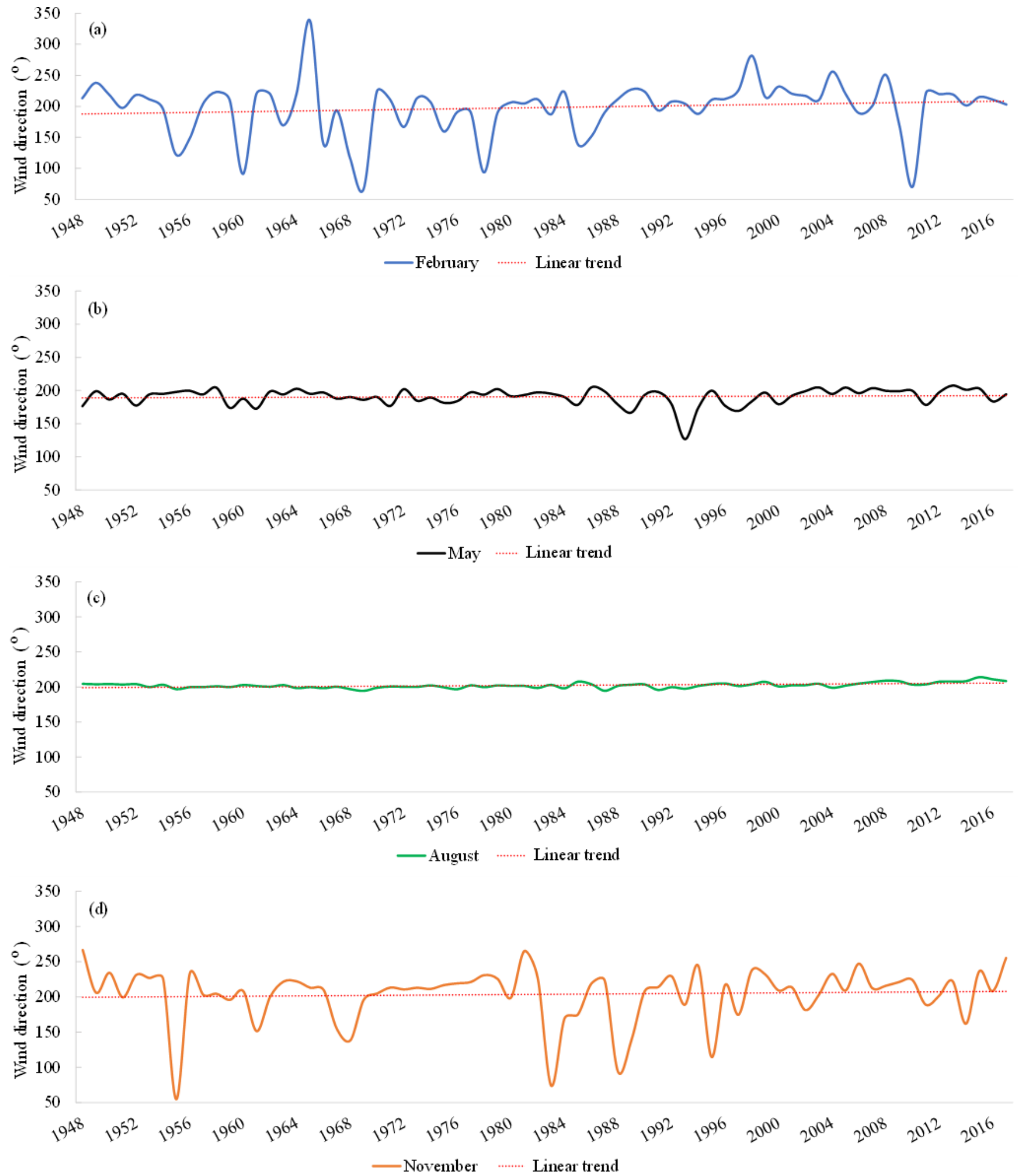

Figure 5. Time series of the wind direction for the central month of each season, with their respective linear regression. Monthly data from 1948 to 2017. (a) Winter (February). (b) Spring (May). (c) Summer (August). (d) Autumn (November).

https://doi.org/10.5194/os-16-951-2020

Ocean Sci., 16, 951-963, 2020 

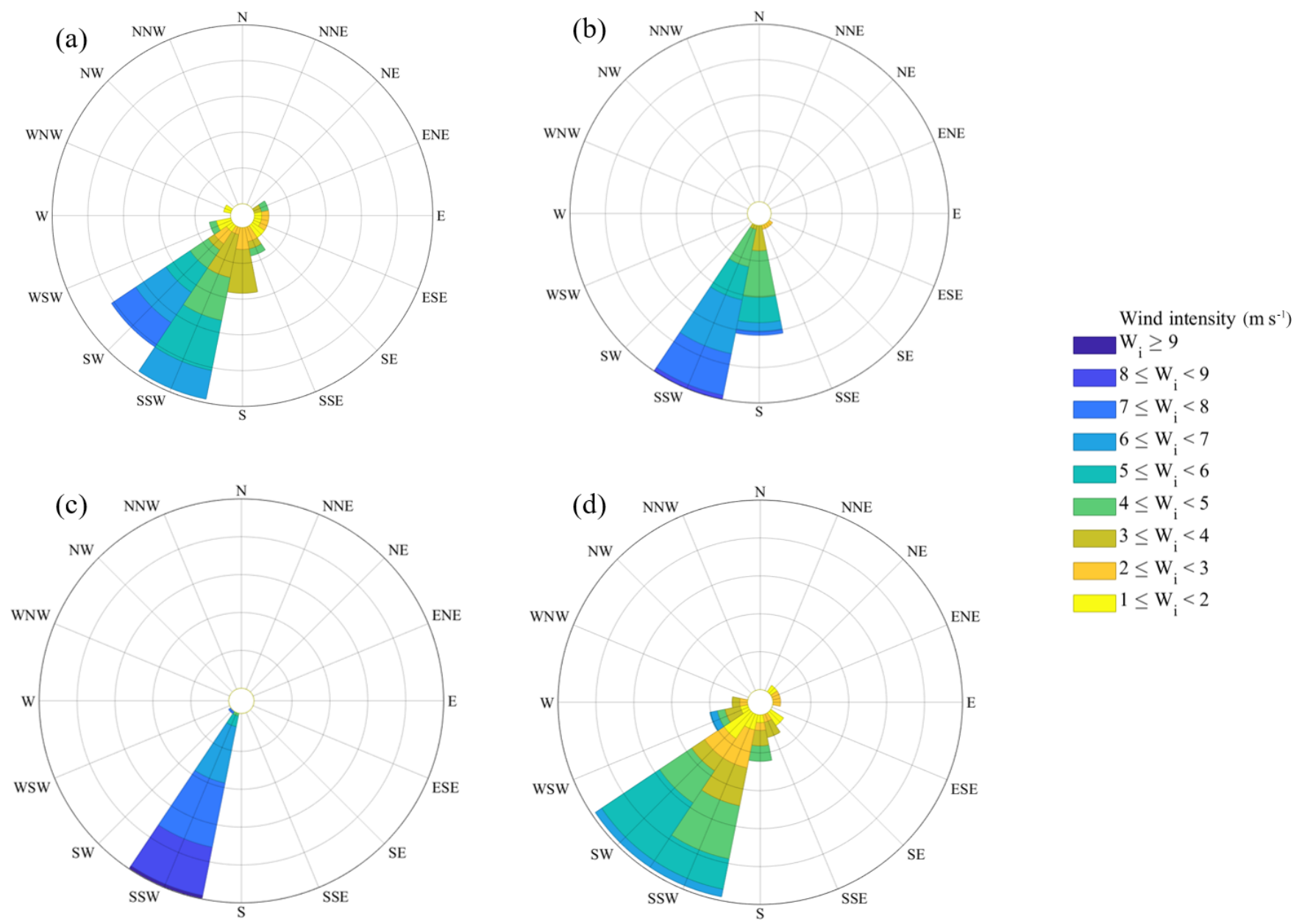

Figure 6. Wind rose for the central month of each season. Monthly data from 1948 to 2017. The wind intensity is given in meters per second by the color bar. (a) Winter (February). (b) Spring (May). (c) Summer (August). (d) Autumn (November).

ever, during the following decades the wind direction mainly rotated clockwise, returning to the NE component and surpassing the wind direction values for the first decades of this study.

Changes during the annual cycle showed a predominant N-NW component from March to June (Fig. 4a, light green). However, the NE component (yellow) prevailed during recent years. Usually, trade winds (yellow) are not present during the winter months. However, a change in the wind direction pattern was observed during the last 2 decades (19982018). This is coincident with the lower variability observed during the trade wind months (July, August, and September) of a fairly marked NE component since the year 2000 . Previous years showed a mixture of light green and yellow (Fig. 4a). The frequency analysis using the wavelet transform (Fig. 4b) shows that the wind direction slightly varied during period of study; thus, blue in Fig. 4b corresponds to the predominance of trade winds in almost all months of the year. On the other hand, yellow and green indicate anomalous variations in wind direction. Also, Fig. 4b shows a no- table change during the last 2 decades, as mentioned before (see Fig. 4a). According to Table 1, the lowest and highest values of the wind direction were reached during the decades of 1998-2007 and 1958-1967, respectively. Examining the slope values, the wind direction rotated counterclockwise during the $50 \mathrm{~s}, 60 \mathrm{~s}, 80 \mathrm{~s}$, and $90 \mathrm{~s}$, while it rotated in the opposite direction during the remaining decades (Fig. $3 b$ and Table 1).

Average wind direction during the central month of winter (Figs. 5a and 6a) and autumn (Figs. 5d and 6d) showed the largest variability. By contrast, spring (Figs. 5b and 6b) and summer (Figs. $5 \mathrm{c}$ and $6 \mathrm{c}$ ) presented a more uniform direction over time. This is corroborated by the seasonal statistical analysis included in Table 2. Quite low positive slopes were observed during all seasons, indicating that the wind direction remained fairly stable over the 70-year period, with a maximum slope of $0.288^{\circ}$ showing a total variation of less than $20^{\circ}$. Spring and summer displayed the lowest values (total variations of 3.27 and $6.56^{\circ}$, respectively), indicating that 

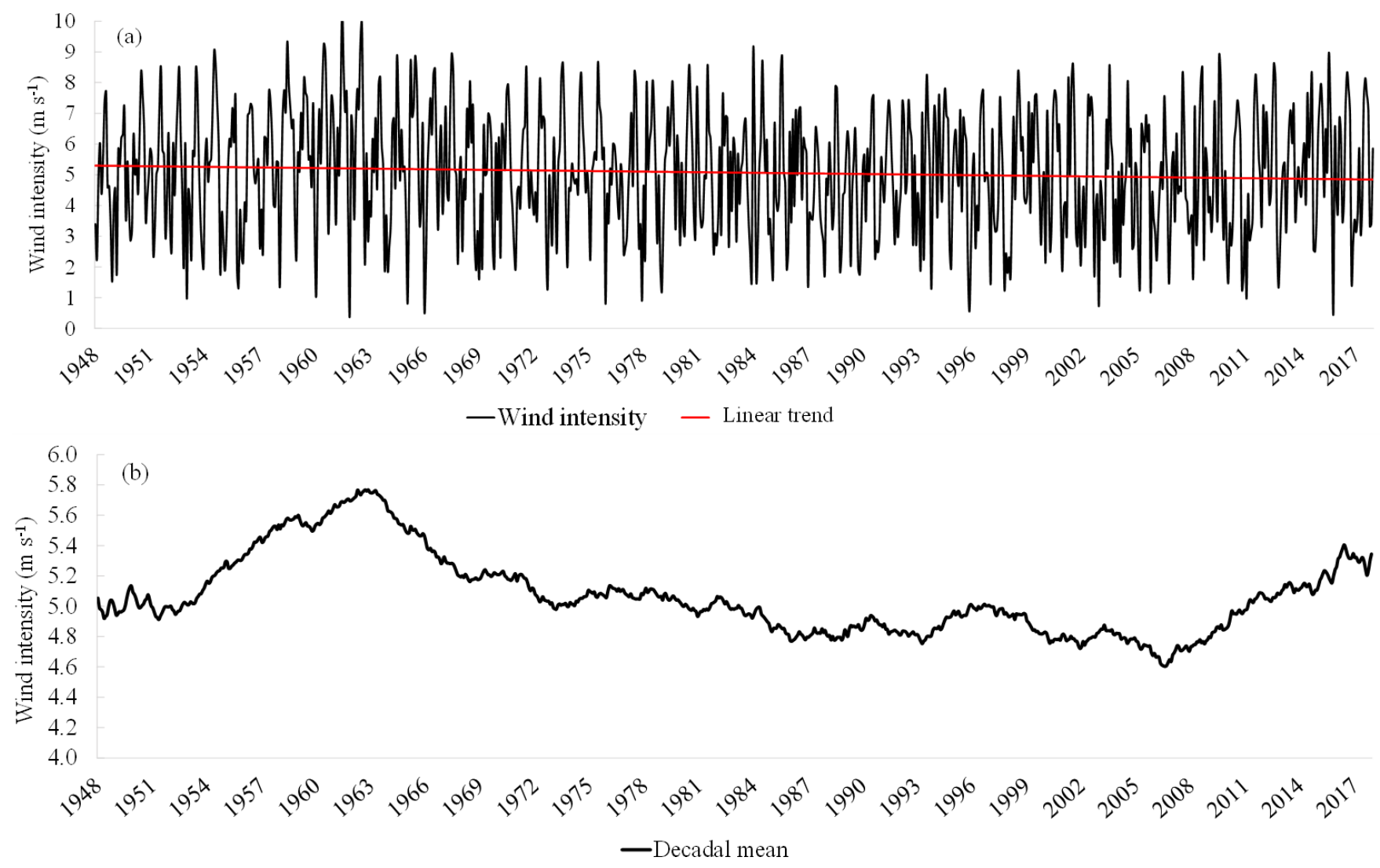

Figure 7. Time series of (a) the wind intensity with its linear regression and (b) the 10-year moving average of the wind intensity.
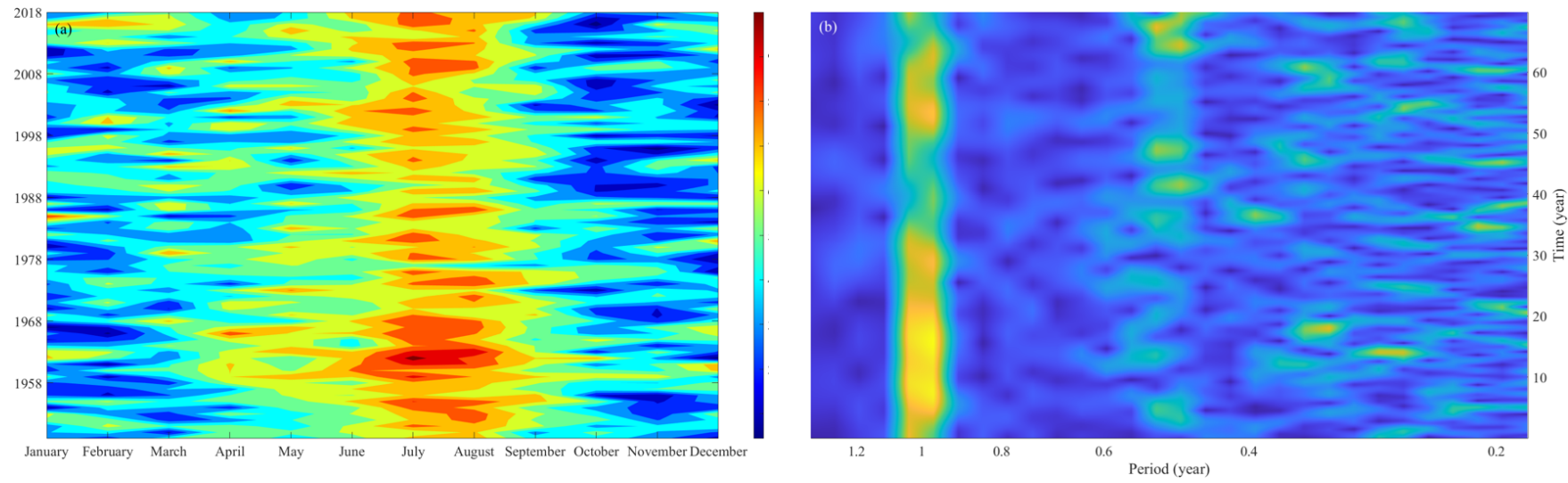

Figure 8. (a) Monthly variations of the wind intensity $\left(\mathrm{m} \mathrm{s}^{-1}\right)(x$ axis) over the years ( $y$ axis). (b) Wavelet analysis of the wind intensity.

trade winds experienced only a slight clockwise rotation during the 7 decades analyzed.

Wind intensity showed a linear regression with a slope of $-0.0005 \mathrm{~m} \mathrm{~s}^{-1}$ for entire period, implying a small decrease of $-0.42 \mathrm{~m} \mathrm{~s}^{-1}$ during the 70 years (Fig. 7a). The average wind intensity value was $5.1 \mathrm{~m} \mathrm{~s}^{-1} \pm 2 \mathrm{~m} \mathrm{~s}^{-1} \mathrm{SD}$. The highest values of the monthly wind intensity were observed during the 60s $\left(10.4 \mathrm{~m} \mathrm{~s}^{-1}\right.$ during July 1961 and $9.91 \mathrm{~m} \mathrm{~s}^{-1}$ in August 1962), while the lowest were found in
December 1961 and October $2015\left(0.44\right.$ and $0.46 \mathrm{~m} \mathrm{~s}^{-1}$, respectively). The 10-year moving average of wind intensity (Fig. 7b) showed a sharp increase until 1963 and mainly a subsequent decrease until 2006. Another persistent increase was observed during the last decade. This behavior is also clearly observed in the seasonal variability over the 70-year period (Fig. 8a). Specifically, the highest values of the wind intensity were observed during the 50s and mainly during the 1960s. During the 1970s the wind intensity remained quite 

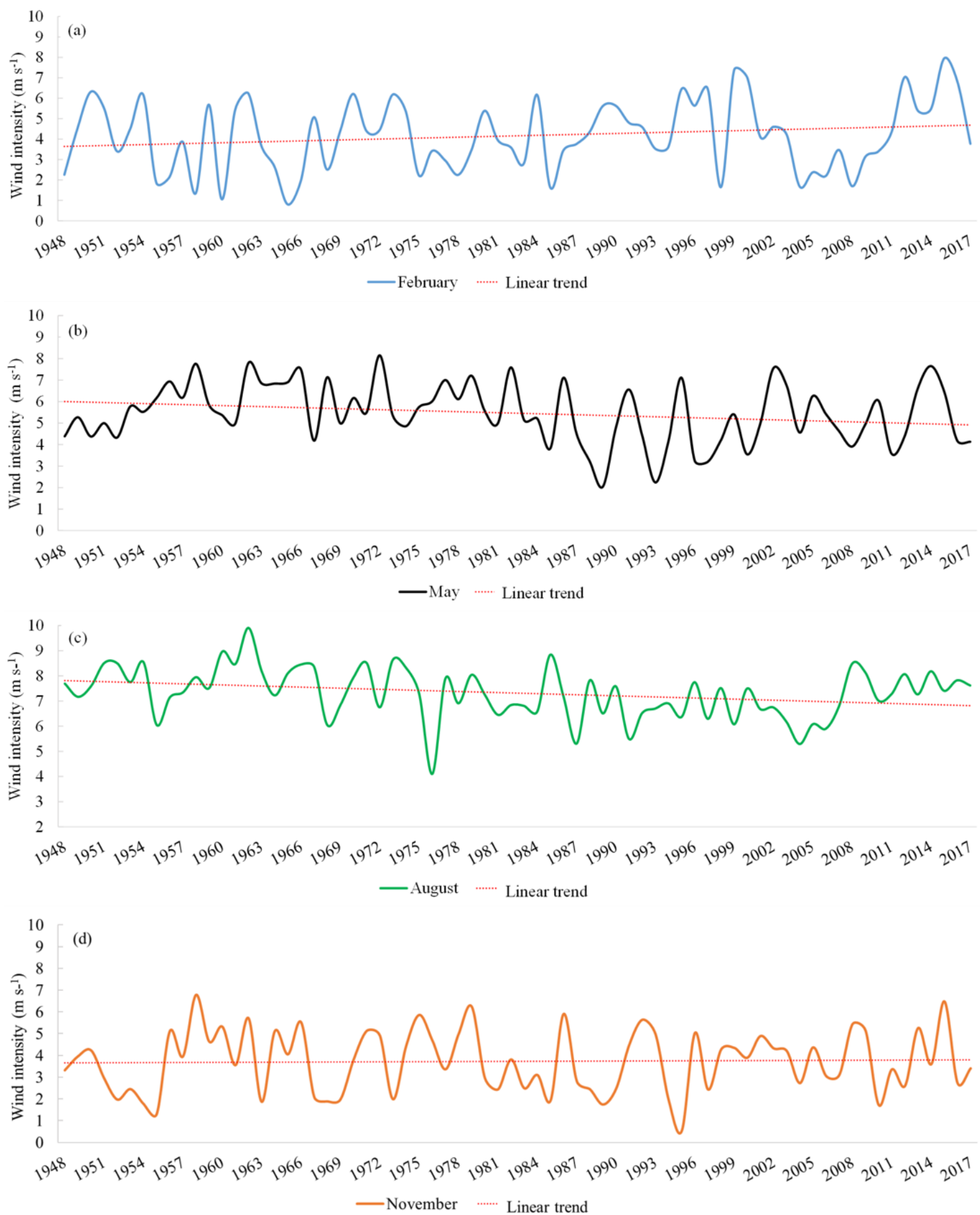

Figure 9. Time series of the wind intensity for the central month of each season with their respective linear regression. Monthly data from 1948 to 2017. (a) Winter (February), (b) spring (May), (c) summer (August), (d) autumn (November).

stable. Then, in the following decades (80s, 90s, and 2000s) the wind intensity was lower than in previous decades. Finally, in recent years, the intensity of the wind has been increasing again (see also Table 3). The periodicity of the wind intensity is shown in Fig. 8b, where the annual pattern is clearly present ( $x$-axis value for the horizontal yellow- orange line) in the wind intensity. In addition, this pattern seems to be discontinuous through the entire time series as revealed in the change in magnitude observed, whereby the annual periodicity changes color from yellow-orange to green-blue. During these situations of weak annual periodic- 

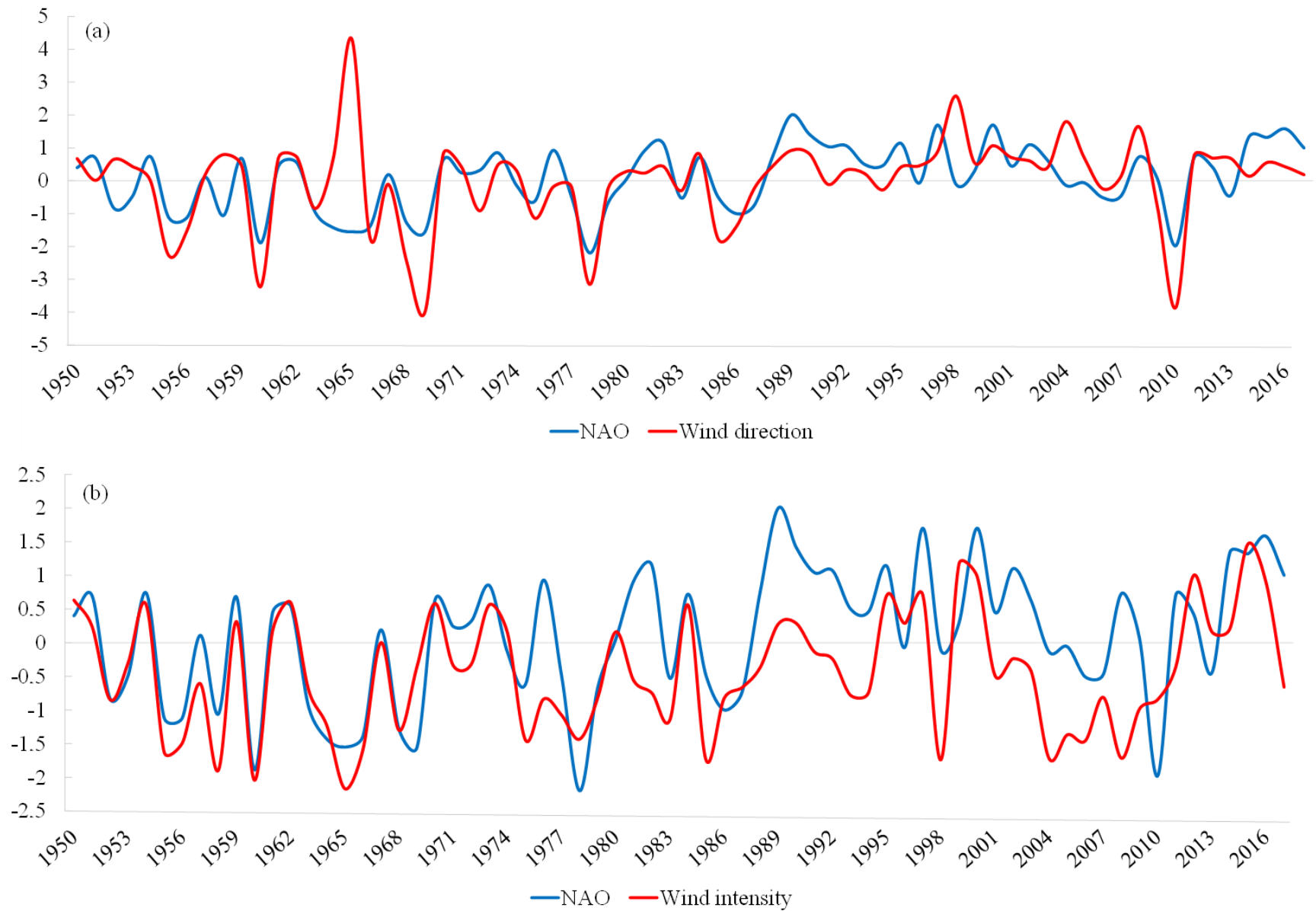

Figure 10. Correlation time series between wind and NAO from 1950 to 2017. (a) Time series of standardized wind intensity and NAO index in winter (February). (b) Times series of standardized wind direction and NAO index in winter (February).

Table 1. Statistical analysis of wind direction (degrees). Values are the result of the decadal study using monthly wind data from 1948 to 2017.

\begin{tabular}{lrrrrrrr}
\hline & $1948-1957$ & $1958-1967$ & $1968-1977$ & $1978-1987$ & $1988-1997$ & $1998-2007$ & $2008-2017$ \\
\hline Min & 54.65 & 70.05 & 14.73 & 57.68 & 65.21 & 11.37 & 46.48 \\
Max & 307.72 & 338.41 & 241.97 & 265.18 & 284.1 & 281.6 & 298.46 \\
Mean & 199.17 & 195.4 & 187.9 & 194.61 & 192.93 & 204.74 & 205.68 \\
SD & 26.26 & 31.31 & 34.91 & 32.24 & 36.11 & 28.84 & 33.79 \\
Slope & -0.1357 & -0.0022 & 0.1236 & -0.0248 & -0.1673 & 0.018 & 0.2318 \\
Offset & 207.38 & 195.53 & 190.42 & 196.11 & 203.06 & 203.65 & 196.66 \\
\hline
\end{tabular}

ity is when a half-year periodicity seems to be the dominant pattern.

Regarding the seasonal study, time series during the central months of each season (Figs. 9 and 6) showed the most intense winds occurring during summer (Figs. 9c and $6 c$ ) and spring (Figs. 9b and $6 \mathrm{~b}$ ) as expected. The lowest intensity was found during autumn (Figs. 9d and 6d) and winter (Figs. 9a and 6a). The seasons displaying the largest intensity (spring and summer) showed sharp negative trends (see also Table 4), indicating that trade winds suffered a decrease in intensity of around $1 \mathrm{~m} \mathrm{~s}^{-1}$ over the 70 -year period analyzed.

Finally, we compared our wind time series with climatic indices such as the North Atlantic Oscillation (NAO) and the Atlantic Multidecadal Oscillation (AMO; Enfield et al., 2001). We found a significant relationship between wind intensity $\left(r^{2}=0.45, p<0.05\right)$ and direction $\left(r^{2}=0.27\right.$, $p<0.05$ ) with the NAO index during winter (Fig. 10), suggesting a close relationship with the general atmospheric circulation. We also found a significant relationship between 


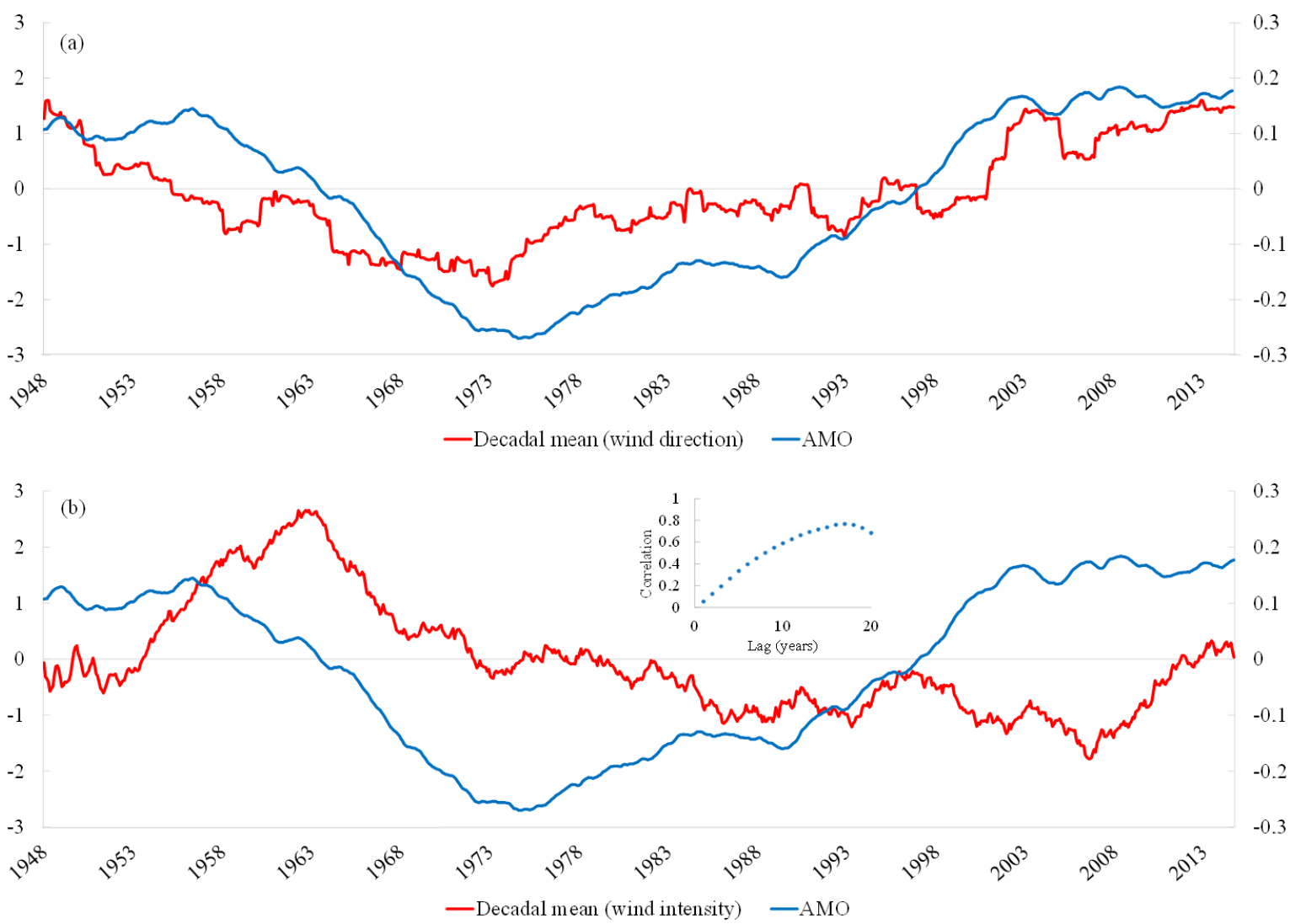

Figure 11. Correlation time series between wind and AMO from 1948 to 2014. (a) Time series of standardized decadal mean wind direction (left axis) and AMO index (right axis). (b) Time series of standardized decadal mean wind intensity (left axis) and AMO index (right axis). Inset shows the correlation with different time lags.

Table 2. Statistical analysis of wind direction (degrees) for the central month of each season (February for winter, May for spring, August for summer, and November for autumn). Monthly wind data from 1948 to 2017 have been used.

\begin{tabular}{lrrrr}
\hline & Feb & May & Aug & Nov \\
\hline Min & 66.1 & 126.7 & 194.5 & 54.6 \\
Max & 338.4 & 207.6 & 214.1 & 266.5 \\
Mean & 198 & 190.6 & 202.3 & 203.6 \\
SD & 43.9 & 12.6 & 3.8 & 39.3 \\
Slope & 0.2988 & 0.0467 & 0.0938 & 0.1194 \\
Offset & 187.42 & 188.96 & 198.93 & 192.32 \\
\hline
\end{tabular}

the wind direction and the AMO index $(r=0.61, p<0.05$; Fig. 11a). However, no correlation was observed between the wind intensity and this oceanic climatic index (Fig. 11b). An increase in the intensity was observed after prolonged positive values of the AMO index, as observed during the 50s and 60 s as well as during the present century. The correlation between the wind intensity and the AMO index changed quantitatively and progressively increased, showing the highest values for a lag over 10 years (Fig. 11b).

\section{Discussion}

In this study, we thoroughly analyzed the meridional and zonal components of the wind north of the Canary Islands for the period from 1948 to 2017 using the NCEP/NCAR database with the aim of visualizing changes in the wind patterns. Over the last 70 years, the wind direction experienced slight oscillations, rotating in a counterclockwise direction for several decades but changing to clockwise in the last decades. Regarding wind intensity, although the total net variation was small, major changes were observed, with regular increases during the 50s and the last decade and decreases during the other periods. We also found a significant correlation between wind direction and the AMO index for the entire period of study. However, the results of the correlation analysis between wind intensity and the AMO index seemed more complex. Bonino et al. (2019) observed different climatic features related to the different EBUSs worldwide. Specifically, they found a negative upwelling trend connected to the low frequency of the AMO index in the Canary Current system. We also observed this relationship for the wind direction (Fig. 11a) but not for the wind intensity (Fig. 11b). The latter increased after prolonged warm- 
Table 3. Statistical analysis of wind intensity $\left(\mathrm{m} \mathrm{s}^{-1}\right)$. Values are the result of the decadal study using monthly wind data from 1948 to 2017.

\begin{tabular}{lrrrrrrr}
\hline & $1948-1957$ & $1958-1967$ & $1968-1977$ & $1978-1987$ & $1988-1997$ & $1998-2007$ & $2008-2017$ \\
\hline Min & 0.98 & 0.44 & 0.81 & 1.2 & 0.55 & 0.72 & 0.46 \\
Max & 9.03 & 10.43 & 8.64 & 9.03 & 8.25 & 8.61 & 8.9 \\
Mean & 5.01 & 5.75 & 4.99 & 4.99 & 4.81 & 4.84 & 5.1 \\
SD & 1.88 & 2.18 & 1.84 & 1.91 & 1.84 & 1.92 & 2.05 \\
Slope & 0.0018 & -0.006 & -0.0006 & -0.0062 & -0.002 & -0.007 & 0.0064 \\
Offset & 4.90 & 6.11 & 5.03 & 5.36 & 4.94 & 5.26 & 4.72 \\
\hline
\end{tabular}

Table 4. Statistical analysis of wind intensity $\left(\mathrm{m} \mathrm{s}^{-1}\right)$ for the central month of each season (February for winter, May for spring, August for summer, and November for autumn). Monthly wind data from 1948 to 2017 have been used.

\begin{tabular}{lrrrr}
\hline & Feb & May & Aug & Nov \\
\hline Min & 0.8 & 2 & 4.1 & 0.6 \\
Max & 7.9 & 8.1 & 9.9 & 6.8 \\
Mean & 4.2 & 5.5 & 7.3 & 3.7 \\
SD & 1.7 & 1.4 & 1 & 1.4 \\
Slope & 0.0151 & -0.0158 & -0.0144 & 0.002 \\
Offset & 3.6281 & 6.0206 & 7.8272 & 3.6573 \\
\hline
\end{tabular}

ing (high AMO index) and decreased after prolonged cooling (low AMO index) over the Atlantic Ocean. We found significant correlations between wind intensity and the AMO index when the time lag between the two parameters was longer than 10 years (Fig. 11b). In this sense, Bjerknes (1964) suggested that the atmosphere drives short-term (interannual) sea surface variability, and the ocean contributes to long-term (multidecadal) sea surface temperature and potentially atmospheric variability. Later, Gulev et al. (2013) observed a lag between the Atlantic multidecadal variability of sea surface temperature and surface turbulent heat fluxes. They found the latter fluxes to be driven by the ocean forcing the atmosphere on timescales longer than 10 years. Those results suggest that the ocean contributes to the multidecadal atmospheric variability with a considerable lag.

Our results also show a high correlation between wind (direction and intensity) and the NAO index, which is most remarkable when analyzing seasonality, displaying a widespread relationship for winter months throughout the period of study (1950-2017). This is due to the intensity of the day-to-day (synoptic) activity in the North Atlantic midlatitudes, which is closely linked to the North Atlantic Oscillation and strongly correlated with surface fluxes on short interannual to intra-decadal timescales (Hurrell, 1995; Eden and Willebrand, 2001; Gulev et al., 2013). This is an expected result as the variability of wind across the Canary archipelago is known to be strongly influenced by the NAO (Hurrell and Deser, 2010; Häkkinen et al., 2011; Barton et al., 2013; Cropper et al., 2014; Azorin-Molina et al., 2018).
Finally, changes in climatic indices such as wind intensity and direction could be the result of changes in the AMO index rather than a simple decreasing trend. Climate in this area of the ocean seemed to be related to the large-scale variability of the Atlantic Ocean rather than a local difference of pressure between the African continent and the Canary Current. The wind variability appeared to be associated with shifts in the seasonal and interannual development and geographic positioning of the four major atmospheric high-pressure systems. However, it is suggested that it is not directly promoted by the increase in the local land-sea temperature difference associated with anthropogenic climate change as hypothesized by Bakun (1990).

In summary, during the last 7 decades, the wind direction has experienced a slight increase with a net trend to rotate clockwise $10.7^{\circ}$, while the intensity achieved a net decrease of $0.42 \mathrm{~m} \mathrm{~s}^{-1}$. However, it is important to emphasize that trade winds were quite stable in direction, but they experienced a significant decrease in intensity of $1 \mathrm{~m} \mathrm{~s}^{-1}$ over the 70 years, although with some intensification during the last 15 years. On the other hand, we found significant correlations between the NAO index and wind (direction and intensity), specifically in winter, indicating that the Canary archipelago is strongly influenced by the NAO. We also found a significant correlation between wind direction and the AMO index for the entire period of study. However, the correlation between wind intensity and the AMO index was found with a lag between the two parameters longer than 10 years. This result suggests that the ocean contributes to multidecadal atmospheric variability with a considerable time lag (Bjerknes, 1964; Gulev et al., 2013). Thus, changes in the wind patterns in the Canary Current seemed to be related to the large-scale variability of the Atlantic Ocean and not to local changes as hypothesized by Bakun.

Data availability. The NCEP data were collected and made freely available by the Physical Sciences Division (PSD) of the National Oceanic and Atmospheric Administration (NOAA) (https://www. esrl.noaa.gov/psd/, last access: 17 March 2020). CCMP version 2.0 vector wind analyses are produced by Remote Sensing Systems (https://www.remss.com, last access: 26 May 2020). The AMO index data are calculated at NOAA/ESRL/PSD1 and available at https://www.esrl.noaa.gov/psd/data/timeseries/AMO/ (last access: 
17 March 2020). The NAO index data are calculated at NOAA and available at https://www.ncdc.noaa.gov/teleconnections/nao/ (last access: 17 March 2020).

Author contributions. SHL, DRE, and JM contributed to designing the research, reviewing the literature, and analyzing the results. $\mathrm{NMB}$ was responsible for the data processing and the generation of a first draft. All the authors were involved in the paper discussion and revision.

Competing interests. The authors declare that they have no conflict of interest.

Acknowledgements. We thank our colleagues from the PASTOR project, ProID2017010072, who provided insight and expertise that greatly assisted the research.

Financial support. This research has been supported by the Department of Economy, Industry, Commerce and Knowledge of the Canary Islands Government, as well as the European Fondo Europeo de Desarrollo Regional (FEDER) (ProID2017010072).

Review statement. This paper was edited by Erik van Sebille and reviewed by two anonymous referees.

\section{References}

Arístegui, J., Barton, E. D., Álvarez-Salgado, X. A., Santos, A. M. P., Figueiras, F. G., Kifani, S., Hernández-León, S., Mason, E., Machú, E., and Demarcq, H.: Sub-regional ecosystem variability in the Canary Current upwelling, Prog. Oceanogr., 83, 33-48, https://doi.org/10.1016/j.pocean.2009.07.031, 2009.

Atlas, R., Hoffman, R. N., Bloom S. C., Jusem, J. C., and Ardizzone, J.: A multiyear global surface wind velocity dataset using SSM/I wind observations, B. Am. Meteorol. Soc., 77, 869-882, 1996.

Atlas, R., Hoffman, R. N., Ardizzone, J., Leidner, S. M., Jusem, J. C., Smith, D. K., and Gombos, D.: A cross-calibrated, multiplatform ocean surface wind velocity product for meteorological and oceanographic applications, B. Am. Meteorol. Soc., 92, 157174, https://doi.org/10.1175/2010BAMS2946.1, 2011.

Azorin-Molina, C., Menendez, M., McVicar, T. R., Acevedo, A., Vicente-Serrano, S. M., Cuevas, E., Minola, L., and Chen, D.: Wind speed variability over the Canary Islands, 1948-2014: focusing on trend differences at the land-ocean interface and below-above the trade-wind inversion layer, Clim. Dynam., 50, 4061-4081. https://doi.org/10.1126/science.247.4939.198, 1990.

Bakun, A.: Global climate change and intensification of coastal ocean upwelling, Science, 247, 198-201, https://doi.org/10.1126/science.247.4939.198, 1990.

Bakun, A. and Nelson, C. S.: The seasonal cycle of windstress curl in subtropical eastern boundary current regions, J.
Phys. Oceanogr., 21, 1815-1834, https://doi.org/10.1175/15200485(1991)021<1815:TSCOWS>2.0.CO;2, 1991.

Barth, J. A., Menge, B. A., Lubchenco, J., Chan, F., Bane, J. M., Kirincich, A. R., and Washburn, L.: Delayed upwelling alters nearshore coastal ocean ecosystems in the northern California current, P. Natl. Acad. Sci. USA, 104, 3719-3724, https://doi.org/10.1073/pnas.0700462104, 2007.

Barton, E. D., Field, D. B., and Roy, C.: Canary current upwelling: more or less?, Prog. Oceanogr., 116, 167-178, https://doi.org/10.1016/j.pocean.2013.07.007, 2013.

Benazzouz, A., Mordane, S., Orbi, A., Chagdali, M., Hilmi, K., Atillah, A., Pelegrí, J. L., and Hervé, D.: An improved coastal upwelling index from sea surface temperature using satellite-based approach - the case of the Canary Current upwelling system, Cont. Shelf Res., 81, 38-54, https://doi.org/10.1016/j.csr.2014.03.012, 2015.

Bjerknes, J.: Atlantic air-sea interaction, Adv. Geophys., 10, 1-82, https://doi.org/10.1016/S0065-2687(08)60005-9, 1964.

Bonino, G., Di Lorenzo, E., Masina, S., and Iovino, D.: Interannual to decadal variability within and across the major Eastern Boundary Upwelling Systems, Sci. Rep-UK, 9, 1-14, https://doi.org/10.1038/s41598-019-56514-8, 2019.

Cropper, T. E., Hanna, E., and Bigg, G. R.: Spatial and temporal seasonal trends in coastal upwelling off Northwest Africa, 1981-2012, Deep-Sea Res., 86, 94-111, https://doi.org/10.1016/j.dsr.2014.01.007, 2014.

Demarcq, H.: Trends in primary production, sea surface temperature and wind in upwelling systems (1998-2007), Prog. Oceanogr., 83, 376-385, https://doi.org/10.1016/j.pocean.2009.07.022, 2009.

Eden, C., and Willebrand, J.: Mechanism of interannual to decadal variability of the North Atlantic circulation, J. Clim., 14, 2266-2280, https://doi.org/10.1175/15200442(2001)014<2266:MOITDV>2.0.CO;2, 2001.

Enfield, D. B., Mestas-Nuñez, A. M., and Trimble, P. J.: The Atlantic multidecadal oscillation and its relation to rainfall and river flows in the continental US, Geophys. Res. Lett, 28, 2077-2080, https://doi.org/10.1029/2000GL012745, 2001.

Gulev, S. K., Latif, M., Keenlyside, N., Park, W., and Koltermann, K. P.: North Atlantic Ocean control on surface heat flux on multidecadal timescales, Nature, 499, 464-467, https://doi.org/10.1038/nature12268, 2013.

Gutiérrez, D., Bouloubassi, I., Sifeddine, A., Purca, S., Goubanova, K., Graco, M., Field, D., Méjanelle, L., Velazco, F., Lorre, A., Salvatteci, R., Quispe, D., Vargas, G., Dewitte, B., and Ortlieb, L.: Coastal cooling and increased productivity in the main upwelling productivity in the main upwelling zone off Peru since the mid-twentieth century, Geophys. Res. Lett., 38, L07603, https://doi.org/10.1029/2010GL046324, 2011.

Häkkinen, S., Rhines, P. B., and Worthen, D. L.: Atmospheric blocking and Atlantic multidecadal ocean variability, Science, 334, 655-659, https://doi.org/10.1126/science.1205683, 2011.

Hoffman, R. N., Leidner, M., Henderson, J. M., Atlas, R., Ardizzone, J. V., and Bloom, S. C.: A two-dimensional variational analysis method for NSCAT ambiguity removal: methodology, sensitivity, and tuning, J. Atmos. Ocean Tech., 20, 585-605, https://doi.org/10.1175/15200426(2003)20<585:ATDVAM>2.0.CO;2, 2003. 
Hurrell, J. W.: Decadal trends in the North Atlantic Oscillation: regional temperatures and precipitation, Science, 269, 676-679, https://doi.org/10.1126/science.269.5224.676, 1995.

Hurrell, J. W. and Deser, C.: North Atlantic climate variability: the role of the North Atlantic Oscillation, J. Marine Syst., 79, 231244, https://doi.org/10.1016/j.jmarsys.2009.11.002, 2010.

IPCC: IPCC Special Report on the Ocean and Cryosphere in a Changing Climate, edited by: Pörtner, H.-O., Roberts, D. C., Masson-Delmotte, V., Zhai, P., Tignor, M., Poloczanska, E., Mintenbeck, K., Alegría, A., Nicolai, M., Okem, A., Petzold, J., Rama, B., and Weyer, N. M., in press, 2019.

Kalnay, E., Kanamitsu, M., Kistler, R., Collins, W., Deaven, D., Gandin, L., Iredell, M., Saha, S., White, G., Woollen, Y., Zhu, J., Chelliah, M., Ebisuzaki, W., Higgins, W., Janowiak, K., Mo, K. C., Ropelewski, J., Wang, J., Leetma, A., Reynolds, R., Jenne, R., and Joseph, D.: The NCEP/NCAR 40-year reanalysis project, B. Am. Meteorol. Soc., 77, 437-472, https://doi.org/10.1175/15200477(1996)077<0437:TNYRP>2.0.CO;2, 1996.

Kelman, I. and Khan, S.: Progressive climate change and disasters: island perspectives, Nat. Hazards, 69, 1131-1136, https://doi.org/10.1007/s11069-013-0721-z, 2013.

Lima, F. P. and Wethey, D. S.: Three decades of high-resolution coastal sea surface temperatures reveal more than warming, Nat. Commun., 3, 704, https://doi.org/10.1038/ncomms1713, 2012.

McGregor, H. V., Dima, M., Fischer, H. W., and Mulitza, S.: Rapid 20th-century increase in coastal upwelling off northwest Africa, Science, 315, 637-639, https://doi.org/10.1126/science.1134839, 2007.

Neuer, S., Cianca, A., Helmke, P., Freudenthal, T., Davenport, R., Meggers, H., Knoll, M., Santana-Casiano, M. J., Gonzáles-Davila, M., Rueda, M. J., and Llinás, O.: Biogeochemistry and hydrography in the eastern subtropical North Atlantic gyre. Results from the European time-series station ESTOC, Prog. Oceanogr., 72, 1-29, https://doi.org/10.1016/j.pocean.2006.08.001, 2007.

Nurse, L. A., McLean, R. F., Agard, J., Briguglio, L. P., DuvatMagnan, V., Pelesikoti, N., Tompkins, E., and Webb, A.: Small islands, in: Climate Change 2014: Impacts, Adaptation, and Vulnerability, Part B: Regional Aspects, Contribution of Working Group II to the Fifth Assessment Report of the Intergovernmental Panel on Climate Change, Cambridge University Press, Cambridge, United Kingdom and New York, NY, USA, 1613-1654, 2014.

Pardo, P. C., Padín, X. A., Gilcoto, M., Farina-Busto, L., and Pérez, F. F.: Evolution of upwelling systems coupled to the long-term variability in sea surface temperature and Ekman transport, Clim. Res, 48, 231-246, https://doi.org/10.3354/cr00989, 2011.
Pauly, D. and Christensen, V.: Primary production required to sustain global fisheries. Nature, 374, 255-257, https://doi.org/10.1038/376279b0, 1995.

Remote Sensing Systems: CCMP version 2.0 vector wind analyses, available at: http://www.remss.com/measurements/ccmp/, last access: 26 May 2020.

Saha, S., Moorthi , S., Pan, H., Wu, X., Wang, J., Nadiga, S., Tripp, P., Kistler, R., Woollen, J., Behringer, D., Liu, H., Stokes, D., Grumbine, R., Gayno, G., Wang, J., Hou, Y., Chuang, H., Juang, H., Sela, J., Iredell, M., Treadon, R., Kleist, D., Van Delst, P., Keyser, D., Derber, J., Ek, M., Meng, J., Wei, H., Yang, R., Lord, S., Dool, H., Kumar, A., Wang, W., Long, C., Chelliah, M., Xue, Y., Huang, B., Schemm, J., Ebisuzaki, W., Lin, R., Xie, P., Chen, M., Zhou, S., Higgins, W., Zou,C., Liu, Q., Chen, Y., Han, Y., Cucurull, L., Reynolds, R., Rutledge, G., and Goldberg M.: The NCEP Climate Forecast System Reanalysis, B. Am. Meteorol. Soc., 91, 1015-1057, https://doi.org/10.1175/2010BAMS3001.1, 2010.

Saha, S., Moorthi , S., Pan, H., Wu, X., Wang, J., Nadiga, S., Tripp, P., Behringer, D., Hou, Y., Chuang, H., Ek, M., Meng, J., Yang, R., Mendez, M., Dool, H., Zhang, Q., Wang, W., Chen, M., and Becker, E.: The NCEP Climate Forecast System Version 2, J. Clim., 27, 2185-2208, https://doi.org/10.1175/JCLI-D-12$00823.1,2014$.

Santos, F., Gómez-Gesteira, M., deCastro, M., and Álvarez, I.: Differences in coastal and oceanic SST trends due to the strengthening of coastal upwelling along the Benguela current system, Cont. Shelf Res., 34, 79-86, https://doi.org/10.1016/j.csr.2011.12.004, 2012a.

Santos, F., Gómez-Gesteira, M., deCastro, M., and Álvarez, I.: Differences in coastal and oceanic SST warming rates along the Canary Upwelling Ecosystem from 1982 to 2010, Cont. Shelf Res., 47, 1-6, https://doi.org/10.1016/j.csr.2012.07.023, 2012b.

Sydeman, W. J., García-Reyes, M., Schoeman, D. S., Rykaczewski, R. R., Thompson, S. A., Black, B. A., and Bograd, S. J.: Climate change and wind intensification in coastal upwelling ecosystems, Science, 345, 77-80, https://doi.org/10.1126/science.1251635, 2014.

Varela, R., Álvarez, I., Santos, F., and Gómez-Gesteira, M.: Has upwelling strengthened along worldwide coasts over 1982-2010?, Sci. Rep-UK, 5, 10016, https://doi.org/10.1038/srep10016, 2015. 